\title{
STRUCTURAL INORGANIC CHEMISTRY AND DIFFRACTION METHODS: METAL-LIGAND BONDS IN POLYNUCLEAR COMPLEXES AND ON METAL SURFACES
}

\author{
R. MASON \\ School of Molecular Sciences, University of Sussex, Brighton BN1 9QJ
}

\begin{abstract}
Coordination compounds, organo-transition metal clusters, metalloproteins and metal surfaces provide many and varied examples of polynuclear complexes. The structural data of such simple examples as dimethylberyllium, triphenylaluminium and their electron-precise counterparts-beryllium dichloride and the aluminium trihalides-can be rationalized through a recognition of the symmetry and occupancy of the bridge molecular orbitals. A simple model of the bonding in binuclear transition metal complexes is summarized. In the case of the redox centres of the metal-sulphur proteins, useful predictions are available from the data on 'model' complexes.

The potential of cluster complexes to stabilize reactive organic species such as benzyne is touched upon by way of an introduction to a brief survey of some recent developments in surface organometallic chemistry.
\end{abstract}

\section{INTRODUCTION}

Since Friedrich and Knipping took the first x-ray diffraction photograph of copper sulphate, crystallographic analyses have provided a major part of the structural framework for the development of theories of the chemical bond in inorganic complexes. This is not the place to recapitulate the early successes which are so well summarized in, for example, Pauling's The Nature of the Chemical Bond and Wells Structural Inorganic Chemistry. And it is inevitable in thinking about more recent progress in the subject that one's personal interests may be too evident. Even so, there is probably general agreement that developments in $\mathrm{x}$-ray data collection methods and in crystallographic computations have been such that inorganic chemists' attitudes to chemical crystallography have changed considerably in the past five or so years. In coordination chemistry, it has become increasingly common to undertake the accurate $\mathrm{x}$-ray analysis of a wide-ranging series of complexes in order to make theoretical correlations much more secure than would be possible from isolated stereochemical observations. This philosophy is well illustrated by the work of Ibers et al. on dioxygen and nitrosyl complexes of iridium(I ${ }^{1}$ and by the systematic studies by Dahl on the geometries of cluster complexes, particularly in regard to their dependence on electronic configuration ${ }^{2}$. Our own work during the past decade has often had its origins in the need to define the structures of unsaturated ligands coordinated to metals ${ }^{3,4}$; when it is possible to relate these results to ligand reactivities, 
the implications to studies of the mechanisms of homogeneous catalysis are obvious.

An understanding of bonding in polynuclear complexes should, by analogy, be of value to the further evolution of models and theories for the interaction between ligands and those metal surfaces of importance in heterogeneous catalysis. In this review, I shall discuss some very recent results in what might usefully be called 'surface organometallic chemistry' but before doing so, relevant results and theories of simpler systems should be discussed.

\section{ELECTRON-DEFICIENT AND ELECTRON-PRECISE BRIDGED BINUCLEAR COMPLEXES}

Amongst the simplest complexes which have been studied and discussed widely are the alkyl- and aryl-bridged complexes of beryllium and aluminium and their halide counterparts. Characteristic structural features of these complexes are the acute bond angle at the bridging ligand and 'short' metalmetal distance in the electron-deficient species and an increase in metal-metal distance by $0.5 \AA$ or so for the electron-precise systems (Figure 1$)^{5-8}$.
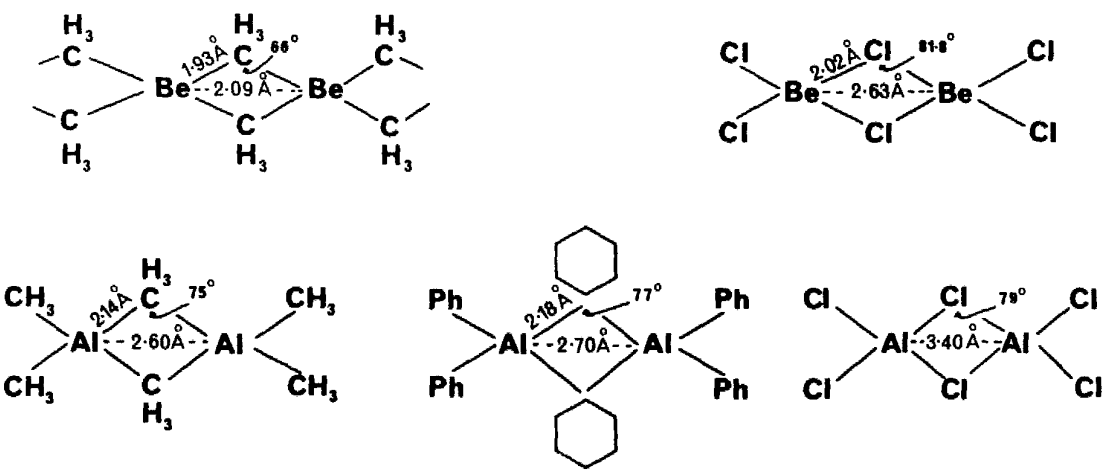

Figure 1. Geometries of some electron-deficient and electron-precise bridged complexes of beryllium and aluminium

Retrospectively, it is surprising that the early comments on the metal-metal distances in $\left(\mathrm{BeCl}_{2}\right)_{n}{ }^{5}$ and $\left(\mathrm{BeMe}_{2}\right)_{n}{ }^{6}$ were so readily and uncritically accepted and extrapolated to related complexes. It was argued ${ }^{5}$ that the acute bond angle in the electron-deficient complexes reflects the need to maximize metal-ligand overlap, and that the additional electrons in beryllium chloride should have served to increase the metal-metal bond order and not to decrease it as is observed. This intuitively attractive suggestion does not, however, stand up to an inspection of the nature and symmetry of the bridge molecular orbitals (Figure 2) ${ }^{9}$. The four electrons allocated to bridge bonds in beryllium dimethyl occupy two molecular orbitals, each of which is bonding with respect to the metals (this apart from any direct metal-metal overlap which has been demonstrated ${ }^{10}$ for diborane). The valence bond structure for the electron-precise structure, has a more general form in molecular orbital theory. For beryllium chloride, the molecular orbitals of beryllium dimethyl 


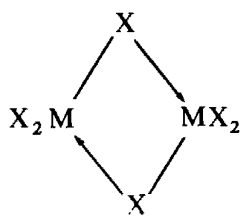

are supplemented by two doubly-filled higher-lying orbitals involving the filled $3 \mathrm{p}$-orbitals on the chlorine atoms; these orbitals are both antibonding withrespect to the metals. The observed geometries have therefore an immediate semiquantitative explanation from simple molecular orbital theory, which also provides an acceptable view on why the 'half-precise' complex, $\mu$ diphenyl amino- $\mu$ methyl-tetramethyldialuminium, has a bridge bond angle
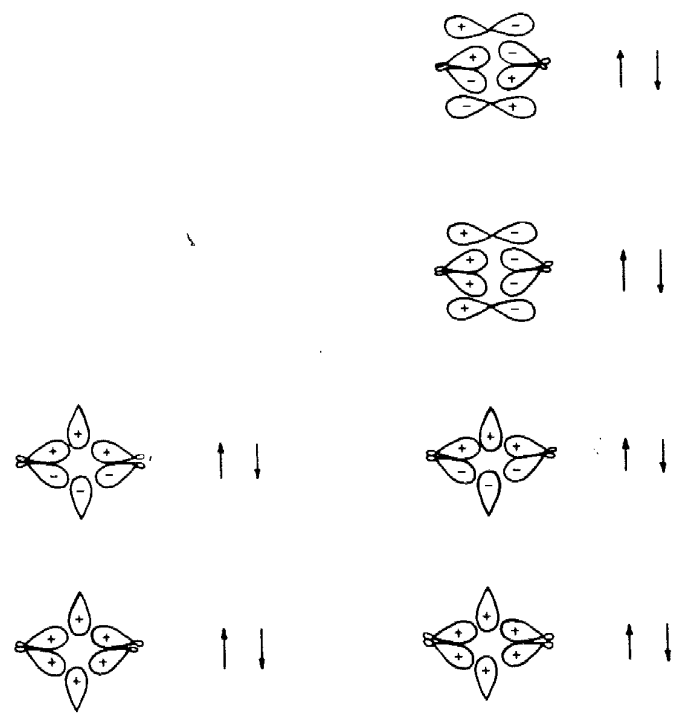

Figure 2. Bridge molecular orbitals in $\left(\mathrm{BeMe}_{2}\right)_{n}$ and $\left(\mathrm{BeCl}_{2}\right)_{n}$

of $79^{\circ}$ at the methyl carbon atom and of $86^{\circ}$ at the nitrogen atom, and an increase of $0.12 \AA$ in the $\mathrm{Al} \ldots \mathrm{Al}$ distance ${ }^{10}$ compared with $\mathrm{Al}_{2} \mathrm{Me}_{6}$. One other subtle point can be mentioned: the conformation of the bridgingphenyl ligands in $\mathrm{Al}_{2} \mathrm{Ph}_{6}$ and the intra-phenyl carbon-carbon bond lengths have been held to indicate the importance of the canonical structure,<smiles>c1ccc([N+](c2ccccc2)(c2ccccc2)c2ccccc2)cc1</smiles> 
In molecular orbital language, we combine some carbon $2 \mathrm{p}$-orbitals into the bridge M.O.'s; such a suggestion is now seen to be also consistent with the $\mathrm{Al}$.... Al distances in $\mathrm{Al}_{2} \mathrm{Me}_{6}(2.60 \AA)$ and in $\mathrm{Al}_{2} \mathrm{Ph}_{6}(2.70 \AA)$.

\section{BRIDGED COMPLEXES OF TRANSITION METALS}

Our scepticism of the traditional overlap explanation for these molecular geometries originated with our observation of the first aryl-bridged complexes of transition metals. In Os $(\mathrm{CO})_{8}\left(\mathrm{PPh}_{2}\right)(\mathrm{Ph})\left(\mathrm{PPhC}_{6} \mathrm{H}_{4}\right)^{12}$ [Figure 3(i)] the Os- $\mathrm{C}(\mathrm{Ph})-\mathrm{Os}$ bond angle is $86^{\circ}$ whereas it is $74^{\circ}$ in $\mathrm{HOs}_{3}(\mathrm{CO})_{8}\left(\mathrm{PPh}_{3}\right)^{-}$ $\left(\mathrm{PPh}_{2} \mathrm{C}_{6} \mathrm{H}_{4}\right)^{13}$ [Figure 3(ii)]. In the tetranuclear ${ }^{14}$ and hexanuclear copper(I) ${ }^{15}$ complexes [Figure $4(i)$ and (ii)], the angles are $70.5^{\circ}$ and $75.5^{\prime}$ respectively. These results obviously suggest that the covalent radii of the bridge and metal atoms are not of major importance in determining bond angles in bridges, a point which is elaborated upon below.
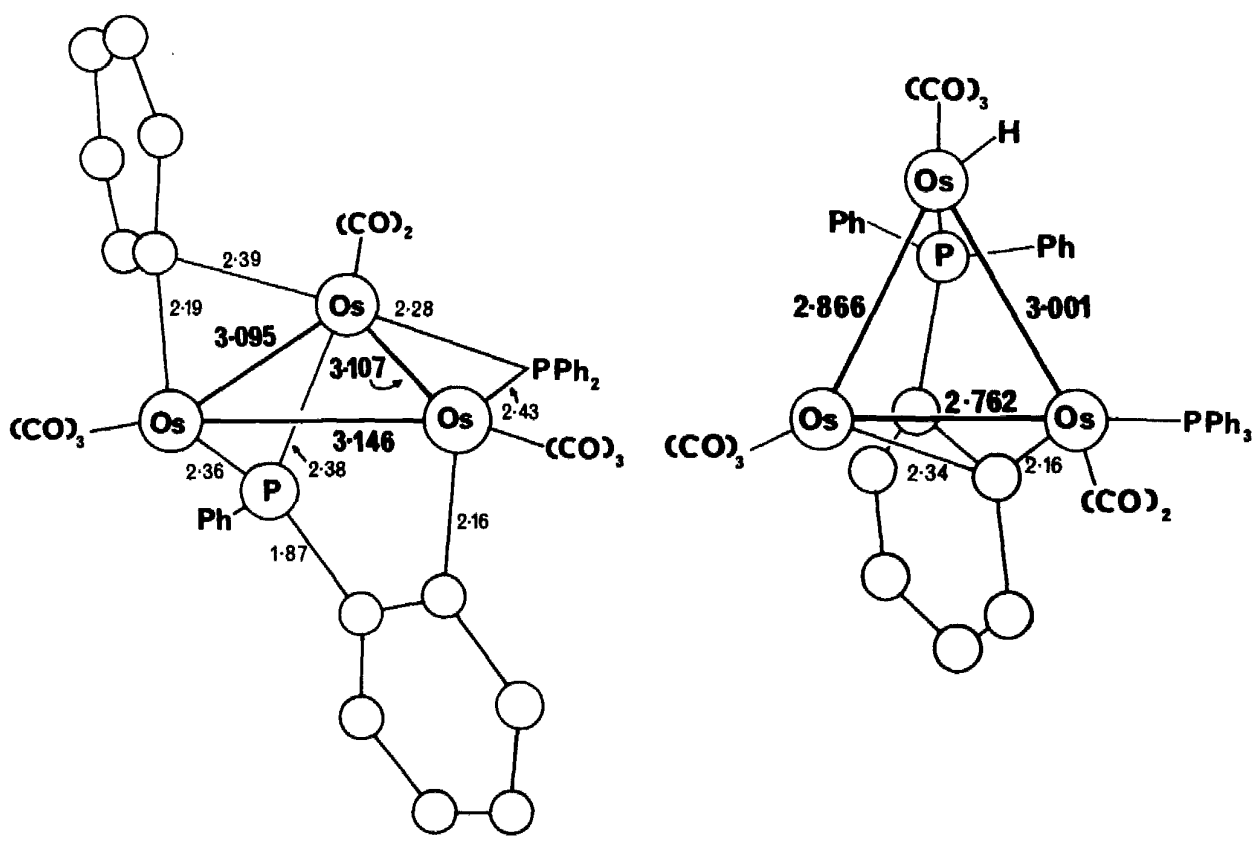

Figure 3. Transition metal-aryl complexes. The structures of $(i) \mathrm{Os}_{3}(\mathrm{CO})_{8}\left(\mathrm{PPh}_{2}\right)(\mathrm{Ph})(\mathrm{PPh}$ $\left.\mathrm{C}_{6} \mathrm{H}_{4}\right)$ and (ii) $\mathrm{HOs}_{3}(\mathrm{CO})_{8}\left(\mathrm{PPh}_{3}\right)\left(\mathrm{PPh}_{2} \mathrm{C}_{6} \mathrm{H}_{4}\right)$

The extension of these views to complexes of transition metals require an explicit consideration of 'd' orbitals. Figure 5 shows an orbital scheme ${ }^{9}$ based entirely on symmetry considerations and reasonable assumptions. Three metal hybrid orbitals, which transform in the same sense as $d_{z^{2}}, d_{x z}$ and $\mathrm{d}_{\mathrm{yz}}$, will form $n$ stable M.O.'s with the metal orbitals and the remaining $[9-(n+3)]$ metal orbitals will be regarded as non-bonding. Clearly, $d_{x z}$ and $d_{z^{2}}$ orbitals play a role which is entirely analogous to that which has been outlined for main-group compounds but the $\mathrm{d}_{\mathrm{yz}}$ orbital is orthogonal to the 
STRUCTURAL INORGANIC CHEMISTRY AND DIFFRACTION METHODS
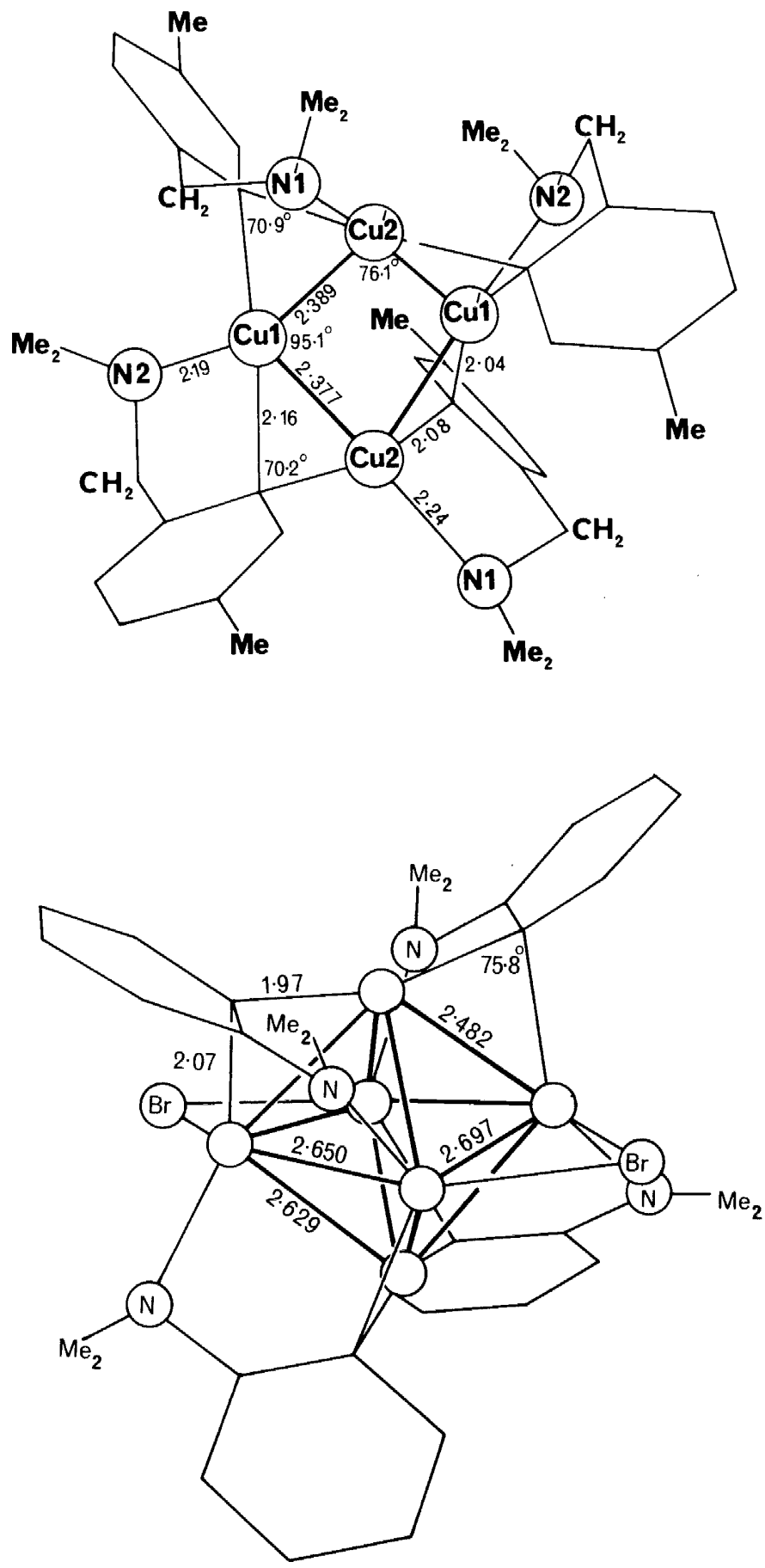

Figure 4. The structures of (i) $\left[4 \mathrm{Me}-2 \mathrm{Cu}-\mathrm{NC}_{6} \mathrm{H}_{4} \mathrm{CH}_{2}\right]_{4}$ and (ii) $\left[\mathrm{Cu}-2 \mathrm{Me}_{2} \mathrm{NC}_{6} \mathrm{H}_{4}\right]_{4}(\mathrm{CuBr})_{2}$ 


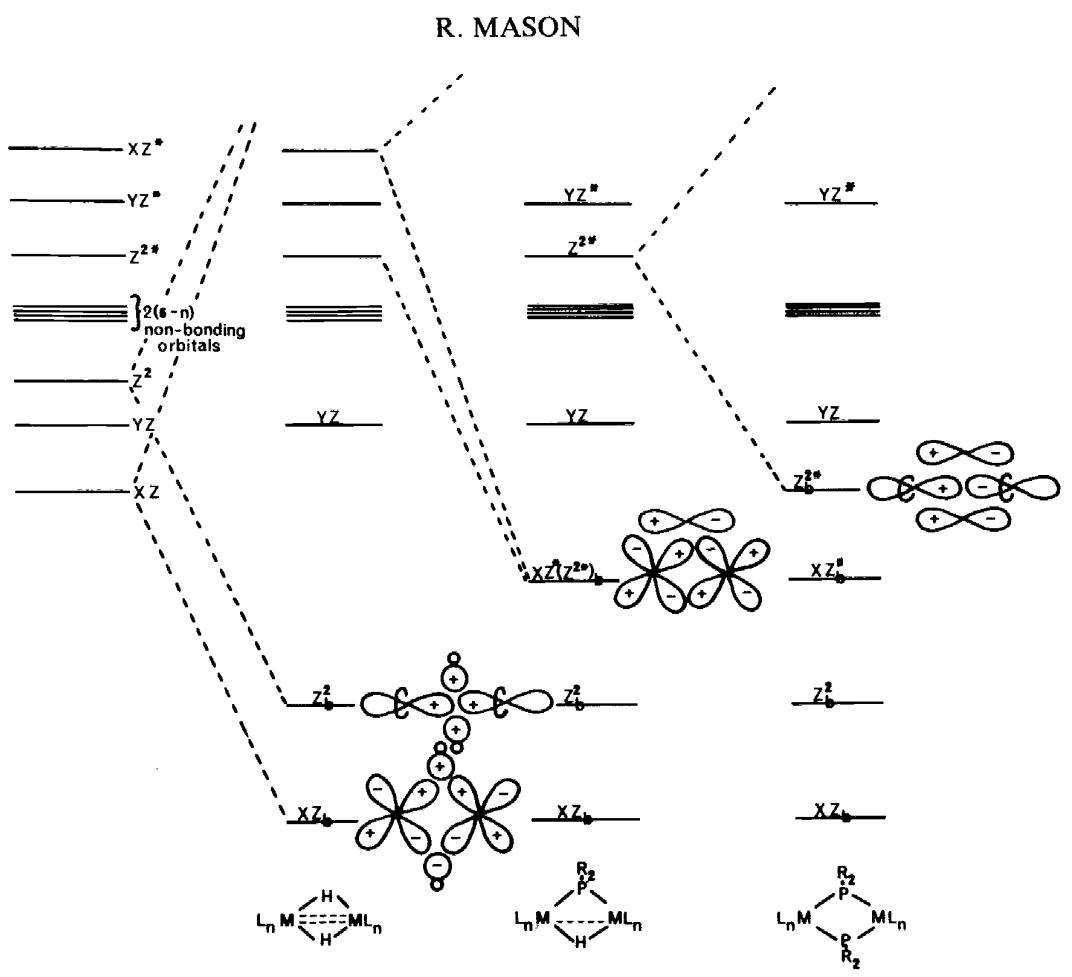

Figure 5. Schematic molecular orbital scheme for binuclear transition metal complexes,

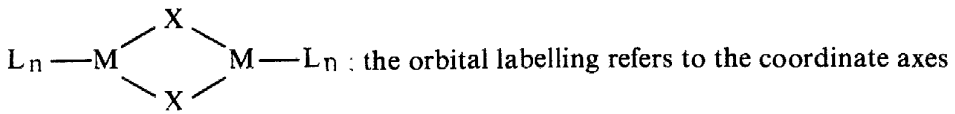<smiles>[X][X][X]</smiles>

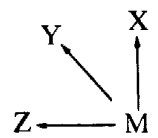

$\mathrm{M}_{2} \mathrm{X}_{2}$ plane and can form in-phase and out-of-phase linear combinations with ligand $\mathrm{p}_{\mathrm{y}}$ orbitals.

The geometries of polynuclear transition metal complexes reflect the electronic configuration of the metals, in addition to the factors discussed earlier, for the main-group elements. A simple example of the former is that the metal-metal distance in $\left\{\left(\pi-\mathrm{C}_{5} \mathrm{H}_{5}\right) \mathrm{Fe}(\mathrm{CO})(\mathrm{SPh})\right\}_{2}$ is $0.44 \AA$ longer than that in $\left\{\left(\pi-\mathrm{C}_{5} \mathrm{H}_{5}\right) \mathrm{Cr}(\mathrm{NO})(\mathrm{SPh})\right\}_{2}{ }^{16,17}$. According to the scheme of Figure 5 , and recognizing that in each case four metal-'terminal' ligand M.O.'s are formed so that initially there will be two non-bonding orbitals on each metal atom, the electronic configuration of the chromium complex is $\left(\mathrm{XZ}_{\mathrm{b}}\right)^{2}\left(\mathrm{Z}_{\mathrm{b}}\right)^{2}$ $\left(\mathrm{XZ}_{\mathrm{b}}^{*}\right)^{2}\left(\mathrm{Z}_{\mathrm{b}}^{*}\right)^{2}(\mathrm{YZ})^{2}$ (non-bonding) ${ }^{8}$ whereas in the iron complex the $\left(\mathrm{YZ}^{*}\right)$ orbital is additionally doubly filled [the capital letters refer to M.O.'s made up from atomic orbitals (small letters)]. The (YZ*) orbital is antibonding with respect to the metals and the increase in metal-metal bond length is rationalized. It is, however, important to note that $\left(\mathrm{YZ}^{*}\right)$ is non-bonding with 
respect to the sulphur $p_{y}$ orbitals and that the $S \ldots S$ and $M-S$ distances should be independent of the metal configuration. Figure 6 shows the good correlation which exists between the metal-metal bond length and the $\mathrm{M}-\mathrm{S}-\mathrm{M}$ bond angles in a number of complexes. Elsewhere, we have defined ${ }^{9}$ a similar correlation for phosphido- and for alkyl- and aryl-complexes of main-group and transition metals and we conclude that the size of the metal atom plays but a minor role in determining the bridge bond angle.

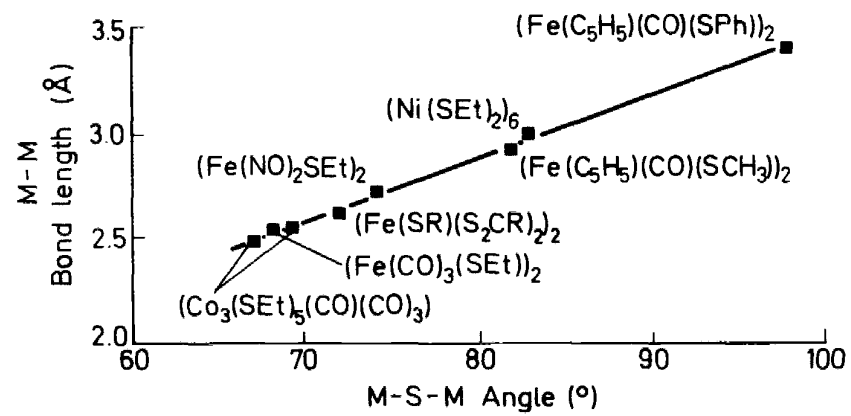

Figure 6. Metal-metal bond lengths and bridge bond angles in some sulphur-bridged complexes

Figure 7 shows a geometrical feature of some bridged trinuclear osmium complexes which are closely analogous to the main-group compounds discussed earlier. The rare gas 'rule' would predict metal-metal bond orders of 2, 1 and 0 for the dihydrido, the hydrido, SEt and the bismethoxy complexes; Figure 5 allows us to write the configurations,

and

$$
\begin{aligned}
& \left.\left(\mathrm{XZ}_{\mathrm{b}}\right)^{2}\left(\mathrm{Z}_{\mathrm{b}}^{2}\right)^{2}(\mathrm{YZ})^{2} \text { (non-bonding }\right)^{8}(\mathrm{YZ})^{2} \\
& \left.\left(\mathrm{XZ}_{\mathrm{b}}\right)^{2}\left(\mathrm{Z}_{\mathrm{b}}^{2}\right)^{2}\left(\mathrm{XZ}_{\mathrm{b}}^{*}\right)^{2}(\mathrm{YZ})^{2} \text { (non-bonding }\right)^{8}\left(\mathrm{YZ}^{*}\right)^{2}
\end{aligned}
$$

$$
\left.\left(\mathrm{XZ}_{\mathrm{b}}\right)^{2}\left(\mathrm{Z}_{\mathrm{b}}^{2}\right)^{2}\left(\mathrm{XZ}_{\mathrm{b}}^{*}\right)^{2}\left(\mathrm{Z}_{\mathrm{b}}^{2 *}\right)^{2}(\mathrm{YZ})^{2} \text { (non-bonding }\right)^{8}\left(\mathrm{YZ}^{*}\right)^{2}
$$

'p'-Orbital donation from the bridge ligand requires successive population of the $\left(\mathrm{XZ}_{\mathrm{b}}^{*}\right)$ and the $\left(\mathrm{Z}_{\mathrm{b}}^{2 *}\right)$ orbitals so that the net bond order in the bismethoxy complex is zero.
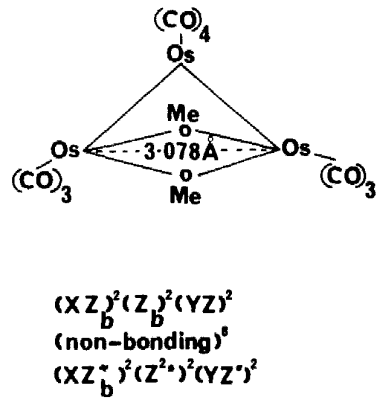

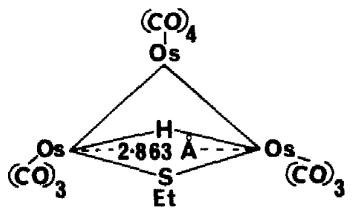

$$
\begin{aligned}
& \left(X Z_{b^{2}}\right)^{2}\left(Z_{b}^{2}\right)^{2}(Y Z)^{2} \\
& \text { (non-bonding)" } \\
& \left(X Z_{b}^{*}\right)^{2}\left(Y Z^{*}\right)^{2}
\end{aligned}
$$

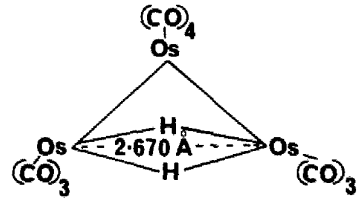

$\left(X Z_{b}\right)^{2}\left(Z_{b}^{2}\right)^{2}(Y Z)^{2}$
(non-bonding $)^{2}$
$\left(Y Z^{*}\right)^{2}$

Figure 7. 'Basal bridge' bond lengths in $\mathrm{H}_{2} \mathrm{Os}_{3}(\mathrm{CO})_{10}, \mathrm{HOs}_{3}(\mathrm{SEt})(\mathrm{CO})_{10}$ and $\mathrm{Os}_{3}(\mathrm{OMe})_{2}(\mathrm{CO})_{10}$ 

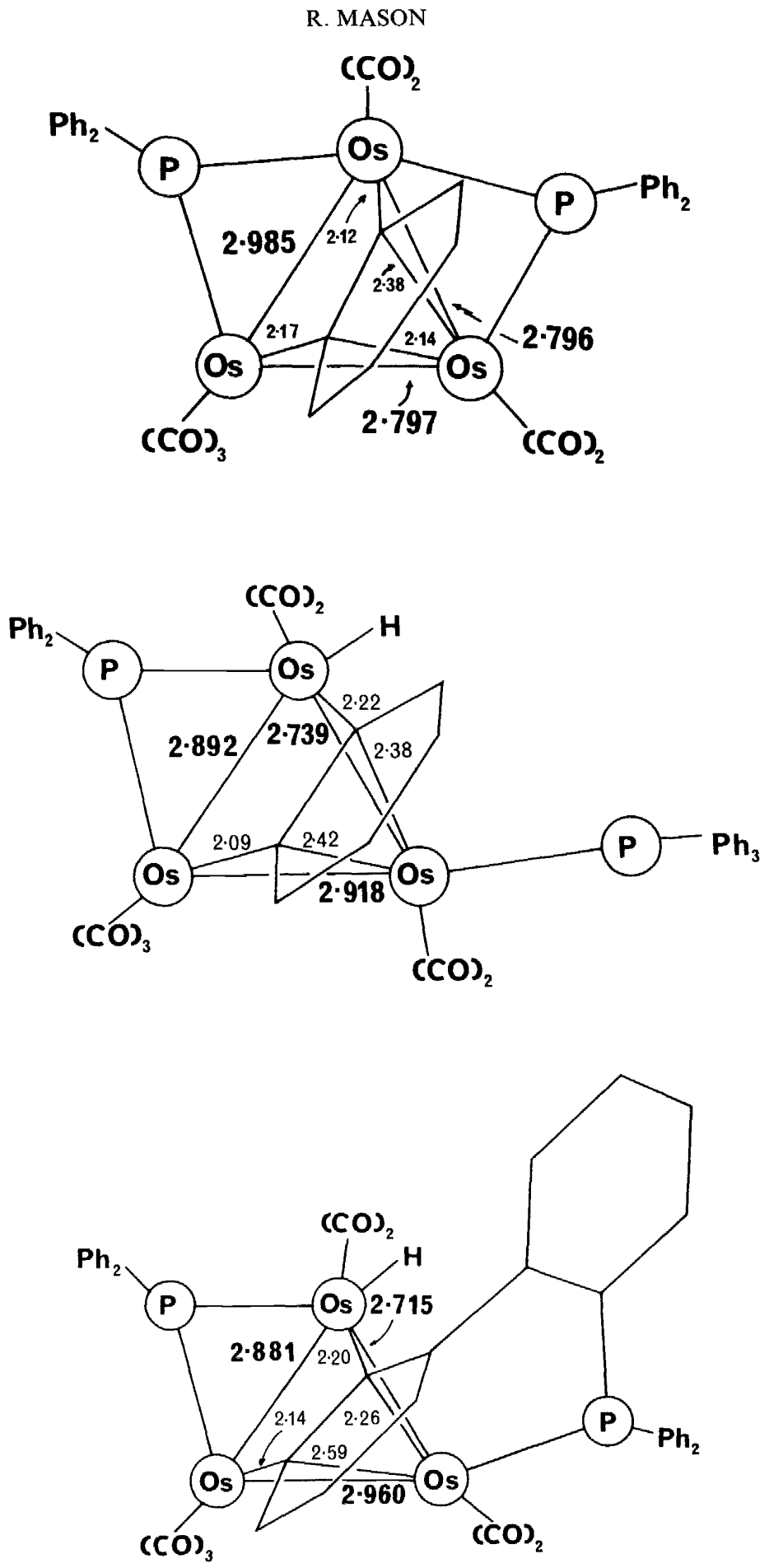

Figure 8. The stereochemistries of some benzyne-osmium compounds 
It is satisfying that a simple valence model is capable of rationalizing, albeit qualitatively, the main structural features of these and other compounds. But when one examines some less symmetrical complexes, it is difficult to develop any coherent picture of the factors influencing their geometries.

A particularly interesting series of complexes in this context and which is illustrative also of the stabilization of unusual, unstable organic moieties by transition metals, is isolated from the oxidative-addition reactions of osmium carbonyl with triphenylphosphine ${ }^{12,13}$. Figure 8 shows the stereochemistries of three benzyne complexes of osmium. Several points should be made. While there are some very considerable variations in individual metal-metal bond lengths, the average metal-metal distance remains remarkably constant at $2.85 \AA$, identical within experimental error to that in $\mathrm{Os}_{3}(\mathrm{CO})_{12}{ }^{18}$. The pattern of the coordination of the benzyne to the cluster is very similar in the three complexes. The dihedral angle between the plane of the aryne and osmium triangle is $69 \pm 3^{\circ}$, a conformation which reflects two osmium atoms being approximately coplanar with the benzyne ligand with mean Os-C bond lengths of $2.16 \AA$; the remaining Os-C bond lengths average $2.39 \AA$. The stereochemistry of the coordinated carbon atoms is thus closer to trigonal pyramidal rather than tetrahedral ; this is different to the situation in acetylene-bridged cluster complexes, a fact we attribute to the need to preserve cyclic delocalization in the aryne and therefore to inhibit further rehybridization at the coordinated carbons.

From the chemical point of view, the observation of an intracluster reaction, involving the oxidative-addition of a benzyne ligand to the $\beta$-carbonhydrogen bond of a terminal triphenylphosphine ligand, is very significant and suggestive of further synthetic work including, perhaps, the in situ buildup of macrocyclic hydrocarbons from coordinated dienes and of interesting heterocyclic systems from, say, coordinated amines.

\section{SOME PROSPECTS}

It is certain that the interaction between chemical crystallography and synthetic and theoretical characterizations of inorganic compounds will continue. It also seems certain that there will be increasing attention to the application of diffraction methods to define significant structures of liquids and solutions. Considerable progress has been made already in our understanding of short-rarige order in simple molecular liquids such as carbon tetrachloride ${ }^{19-21}$ and even their dynamics are becoming clearer through measurement of the quasi- and in-elastic scattering of neutrons. There remains considerable disagreement about the structure of water $^{22,23}$ but again ambiguities are being removed through a combination of $\mathrm{x}$-ray and neutron scattering data.

But to return to my main theme, there can also be little doubt that diffraction methods will be, indeed already are, of paramount importance in two apparently unrelated fields-polynuclear cluster complexes in biomacromolecules and surface organometallic chemistry. These have one important point in common : an understanding of structure and mechanism will carry us much closer to an intimate understanding of catalysis in its widest sense. 


\section{CLUSTER COMPLEXES IN REDOX PROTEINS}

The x-ray crystallographic method is seen at its most powerful when it is defining the structure of proteins and enzymes. Apart from the major milestones that have been passed in heme-protein chemistry, the results of the past two years relating to the nature of the redox centres in iron-sulphur proteins are very interesting for the transition metal chemist, as well as the protein crystallographers. From the inorganic point of view, rubredoxin is the simplest iron-sulphur protein whose chromophore, we know from Jensen's work ${ }^{24}$, to be a distorted tetrahedron of cysteine sulphurs about the single iron atom. The distortion must, I believe, have its origins in the protein chain conformation since it is quite unlike those distortions in simple complexes of iron which are often attributed to Jahn-Teller effects but may be due, in part, to crystal packing. No unambiguous structural data are to hand on the two-iron, labile-sulphur proteins found in plants, but there is much spectroscopic and magnetic evidence to support the structure:

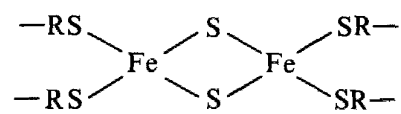

There is strong antiferromagnetic coupling between the two formal ferric ions of the oxidized protein but one-electron reduction is localized at one iron atom ${ }^{25-27}$. In the so-called high potential protein from the photosynthetic bacterium Chromatium, Kraut and his co-workers ${ }^{28}$ have shown that the four irons and labile sulphurs have a cubane arrangement, the coordination about the irons being completed by cysteine sulphurs (Figure 9).

Jensen and Sieker ${ }^{29}$ have shown that the eight-iron bacterial ferredoxin from Micrococcus aerogenes has two very similar cluster arrangements separated by $12 \AA$; the strong homology in the amino acid sequences of fivebacterial ferredoxins argue strongly that they are all structurally very similar and indeed we have shown that this is the case for the protein from C. acidiurici.

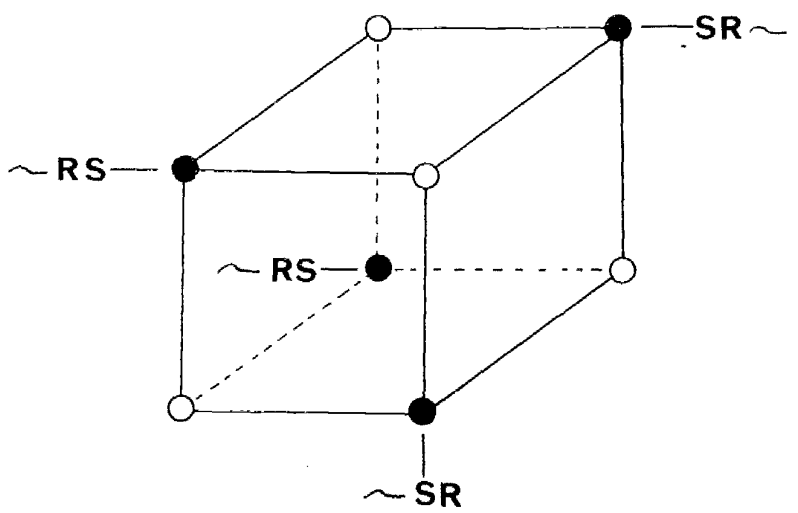

Figure 9. The iron-sulphur cubane cluster in non-heme proteins 
This knowledge prompts the important question, why should the redox potentials of the Chromatium and Micrococcus proteins, which are respectively $+0.3 \mathrm{~V}$ and $-0.4 \mathrm{~V}$, be so different? At the present state of the crystallographic analyses, the $\mathrm{Fe}-\mathrm{S}$ clusters in both complexes are symmetrical interacting tetrahedra with a mean $\mathrm{Fe}-\mathrm{Fe}$ distance of $3.06 \AA$ in the high potential system and $2.85 \AA$ in $M$. aerogenes ${ }^{30}$. These distances refer to proteins in their reduced and oxidized states respectively but it seems, from the x-ray data on the Chromatium protein at least, that oxidation-reduction has little effect on the stereochemistry of the cluster. This is not difficult to understand when the results on 'model' systems are recollected. The stereochemistry of $\left.\left[\left(\pi-\mathrm{C}_{5} \mathrm{H}_{5}\right) \mathrm{FeS}\right)\right]_{4}{ }^{31}$ is such that only one iron-iron bond of length $2.65 \AA$ is formed in the cluster, a feature which can be rationalized in terms of the eighteen-electron rule. In $(-\mathrm{RSFeS})_{4}$, each iron atom will have an effective sixteen-electron configuration when each iron makes three metal-metal bonds. One-electron reduction will probably distort the cluster towards $D_{2 \mathrm{~d}}$ symmetry but with only a small increase in the average metal-metal bond length. The protein clusters and $\left[\left(\pi-\mathrm{C}_{5} \mathrm{H}_{5}\right) \mathrm{FeS}\right]_{4}$ have one common feature, the lack of any good $\pi$-acid ligands. Reduction will localize the electron in the cluster and in $\left[\left(\pi-\mathrm{C}_{5} \mathrm{H}_{5}\right) \mathrm{FeS}\right]_{4}$ this must imply a weakening of the one metalmetal bond. By contrast, the other model system $\left[\left(\mathrm{CF}_{3}-\mathrm{SC}=\mathrm{CS}-\mathrm{CF}_{3}\right) \mathrm{FeS}\right]_{4}{ }^{32}$ can be predicted to have two metal-metal bonds (sixteen electrons per iron) and the mono- and di-anion will be similar since the strongly $\pi$-accepting dithietene ligands will remove electrons from antibonding cluster orbitals. Magnetic circular dichroism studies bear out these suggestions.

It must be assumed that the difference of $0.2 \AA$ in the mean $\mathrm{Fe}-\mathrm{Fe}$ bond lengths of the two protein clusters reflects the differing amino acid sequences which could affect, both electronically and sterically, the cysteine donor properties. Clusters with large metal-metal bond distances will be relatively easy to reduce.

Further work on these and other non-heme proteins will be rewarding. The role of aromatic residues adjacent to the clusters in the electron transfer process needs to be defined carefully - just as in a number of heme proteins such as the cytochromes, their business may be one of acting as electron 'trap doors' ${ }^{33}$. It is, after all, easy to envisage these clusters acting as twoelectron acceptors; the fact that they do not implies that conformational changes in the protein occur on one-electron transfers which are, perhaps, sufficient to remove the aromatic residue from the immediate environment of the cluster and short-circuit the electron transfer pathway.

One of the proteins which makes up the enzyme complex known as nitrogenase is a four-iron-four-labile-sulphide protein ${ }^{34}$ and may contain the cubane cluster. It would be very optimistic, however, to think that substantial progress towards the structural elucidation of nitrogenase will be made in the near future by the crystallographic method.

\section{ORGANOMETALLIC CHEMISTRY OF TRANSITION , METAL SURFACES}

Apart from enzymic systems such as nitrogenase, platinum metal is probably the most versatile catalyst. Yet in spite of many physicochemical studies of 
heterogeneous catalysis, unequivocal evidence as to the nature of chemisorbed species on metals is not available. Infrared spectroscopy is indicative of terminal and bridging carbonyl groups when carbon monoxide is chemisorbed on platinum ${ }^{35}$. It also argues against ethylene, for example, being chemisorbed as a mononuclear $\pi$-complex ${ }^{36}$ but no quantitative stereochemistry of the metal-ligand bond(s) can be determined by this method.

The method which, in principle, can be used to define the geometries of adsorbate and adsorbent is low-energy electron diffraction (1.e.e.d.). A single crystal face, with or without adsorbate, is used to scatter electrons whose energies range from about $20 \mathrm{eV}$ up to $c .300 \mathrm{eV}$. The technique is an old one but its potential in surface physies and chemistry has been limited by the fact that a rigorous exploitation of l.e.e.d. intensities must recognize the possible contributions of multiple and inelastic scattering to the scattered intensities. Non-empirical calculations are becoming available for simple surfaces and for simple overlay structures, such as sodium deposited on nickel $^{37}$, but in our present state of knowledge regarding the interaction of platinum metal with unsaturated ligands, we approached the problem in an alternative way, namely through the application of Fourier analysis to l.e.e.d. intensities ${ }^{38,39}$.

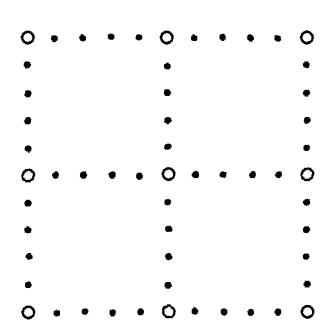

Pt $(100) 5 \times 1$

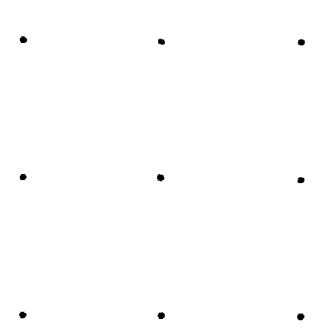

$\operatorname{Pt}(100)-\operatorname{co} 1 \times 1$

Figure 10. Schematic representation of the low-energy electron diffraction patterns of $(a)$ the clean $\mathrm{Pt}(100)$ surface and $(b)$ the $\mathrm{Pt}(100)+$ carbon monoxide surface

Figure 10 shows in a schematic way, the l.e.e.d. patterns for the clean $\operatorname{Pt}(100)$ surface and its modification following adsorption of carbon monoxide. The anomalous $(5 \times 1)$ surface structure of platinum is shown also by gold $^{40}$ and one explanation is that the top layer of the clean surface is a hexagonal close-packed arrangement rather than the face-centred cubic array of the bulk structure. The $(1 \times 1)$ pattern of $\mathrm{Pt}(100)$-CO defines the two dimensional unit mesh of the surface as identical, within experimental error, to that which can be deduced from bulk measurements $(2.77 \AA)$. Fourier transformation of the l.e.e.d. intensity profiles provides a series which is rather similar to the Patterson function of $x$-ray crystallography and, in the case of Pt(100)-CO, this can be immediately interpreted in terms of the surface structure shown in Figure $11^{39}$.

It is only the geometry of the bridging carbonyl groups that deserve special comment. They could have bridged platinum atoms separated by $2.77 \AA$, for that is precisely the situation in tetrabis(phenyldimethylphosphine)tetraplatinum pentacarbonyl ${ }^{41}$ (the bridging carbonyl frequencies of this complex 


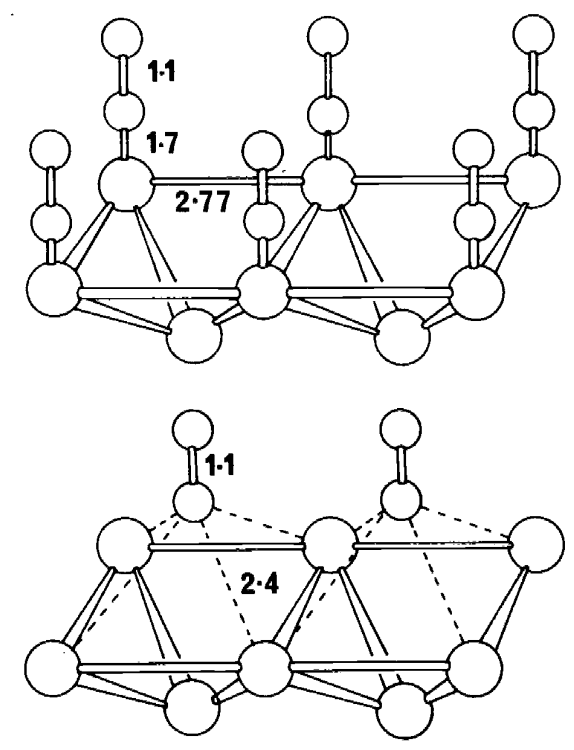

Figure 11. The structural arrangement of chemisorbed carbon monoxide on the $\mathrm{Pt}(100)$ surface

are similar to those observed in the heterogeneous complex). In fact, the structure of Figure 11 is identical to that predicted by Bond ${ }^{42}$ who pointed out that the direction of emergence of metal orbitals from the (100) face of an f.c.c. metal requires that a bridging carbonyl group must occupy a site of four-fold and not two-fold symmetry.

$\mathrm{X}$-ray induced electron emission spectroscopy has also been used to show ${ }^{35}$ that, as expected, the net charge transfer, during chemisorption, is from the metal to the carbonyl ligands-quantitatively, the sub-valence and core electron shifts are similar to those observed in $\mathrm{Ni}(\mathrm{CO})_{4}$ and $\mathrm{Cr}(\mathrm{CO})_{6}{ }^{43}$. The power of combined l.e.e.d. and e.s.c.a. measurements to define the geometry and electronic structure of ligand-metal surface interactions is beginning to be evident. But the carbon monoxide case is a rather special one. It is obvious now that it will be more difficult in the case of the adsorption of alkenes and aromatic molecules. Here, there is strong evidence that dissociative chemisorption is taking place with resulting complications on the interpretation of the diffraction and spectroscopic experiments.

Most of this work summarized here has been sponsored by the Science Research Council. I am indebted to my colleagues in Sheffield and Sussex during the past three years-Drs. T. A. Clarke, G. J. Gainsford, M. Guss, P. B. Hitchcock, P. Ireland, D. M. P. Mingos, M. Tescari, M. Thomas and J. Zubieta-for all of their contributions and discussions.

\section{REFERENCES}

1 D. M. P.Mingos and J. A. Ibers, Inorg. Chem., 10, 1479 (1971); J. A. McGinnety, N. C. Payne and H. A. Ibers, J. Am. Chem. Soc., 91, 6301 (1969) and references therein.

2 D. L. Stevenson, C. H. Wei and L. F. Dahl, J. Am. Chem. Soc., 93, 6207 (1971); C. E. Strouse and L. F. Dahl, J. Am. Chem. Soc., 93, 6032 (1971) and references therein. 


\section{R. MASON}

3 M. R. Churchill and R. Mason, Adv. Organomet. Chem., 5, 93 (1967).

${ }^{4}$ R. McWeeny, R. Mason and A. D. C. Towl, Discussions Faraday Soc., 47, 21 (1969).

${ }^{5}$ R. E. Rundle and P. H. Lewis, J. Chem. Phys., 20, 132 (1952).

6 A. I. Snow and R. E. Rundle, Acta Cryst., 4, 348 (1951).

7 J. F. Malone and W. S. McDonald, Chem. Commun., 444 (1967); 280 (1970).

8 Interatomic Distances, Spec. publication No. 11, Chemical Society, London (1958).

9 R. Mason and D. M. P. Mingos, J. Organomet. Chem., in the press.

10 W. E. Palke and W. N. Lipscomb, J. Am. Chem. Soc., 88, 2384 (1966).

11 V. R. Magnison and G. D. Stucky, J. Am. Chem. Soc., 91, 2544 (1969).

12 C. W. Bradford, R. S. Nyholm, G. J. Gainsford, J. M. Guss, P. R. Ireland and R. Mason, J.C.S. Chem. Commun., 87 (1972).

13 G. J. Gainsford, J. M. Guss, P. R. Ireland, R. Mason, C. W. Bradford and R. S. Nyholm, $J$, Organomet. Chem., in the press.

14 J. M. Guss, R. Mason, I. Sotofte, G. van Koten and J. G. Noltẹs, J.C.S. Chem. Commun., 446 (1972).

15 J. M. Guss, R. Mason, K. M. Thomas, G. van Koten and J. G. Noltes, J. Organomet. Chem., in the press.

16 N. G. Connelly and L. F. Dah1, J. Am. Chem. Soc., 92, 7472 (1970).

17 A. T. McPhail and G. A. Sim, J. Chem. Soc. $(A), 1858$ (1968).

18 E. R. Corey and L. F. Dahl, Inorg. Chem., 1, 521 (1962).

19 A. H. Narten, M. D. Danford and H. A. Levy, J. Chem. Phys., 46, 4875 (1967).

20 P. A. Egelstaff, D. I. Page and J. G. Powles, Mol. Phys., 20, 881 (1971).

21 P. R. Ireland, R. Mason and A. I. M. Rae, Mol. Phys., in the press.

22 A. H. Narten, M. D. Danford and H. A. Levy, Discussions Faraday Soc., 43, 97 (1967).

23 D. I. Page and J. G. Powles, Mol. Phys., 21, 901 (1971).

24 J. R. Herriot, L. C. Sieker, L. H. Jensen and W. Lovenberg, J. Mol. Biol., 50, 391 (1970).

25 G. Palmer, W. R. Durham, J. A. Fee, R. H. Sands, T. lizuka and T. Yanetani, Biochim. Biophys. Acta, 245, 201 (1971).

${ }^{26}$ W. R. Durham, A. J. Beardin, I. T. Salmeen, G. Palmer, R. H. Sands, W. H. Orme-Johnson, H. Beinert, Biochim. Biophys. Acta, 253, 134 (1971).

27 J. Fritz, R. Anderson, J. A. Fee, G. Palmer, R. H. Sands, J. C. M. Tsibus, I. C. Gunsalus, W. H. Orme-Johnson and H. Beinert, Biochim. Biophys. Acta, 253, 110 (1971).

28 C. W. Carter, S. T. Freen, Ng. H. Xuong, R. A. Alden and J. Kraut, Coldspring Harbour Symposium, No. 36 (1971).

29 L. C. Sieker, E. Adman and L. H. Jensen, Nature, 235, 40 (1972).

${ }^{30}$ L. C. Sieker and L. H. Jensen, private communication.

31 C. H. Wei, G. R. Wilkes, P. M. Treichel and L. F. Dahl, Inorg. Chem., 5; $900(1966)$; R. A. Schunn, C. J. Fritchie and C. T. Prewitt, Inorg. Chem., 5, 892 (1966).

32 A. L. Balch, J. Am. Chem. Soc., 91, 6962 (1969).

33 R. J. P. Williams, Inorg. Chim. Acta Rev., 5, 137 (1971).

34 R. R. Eady, B. E. Smith, K. A. Cook and J. R. Postgate, Biochem. J., in the press.

${ }^{35}$ R. P. Eischens, Accounts of Chemical Research, 5, 74 (1972).

36 N. Sheppard, Discussions Faraday Soc., 41, 177 (1966).

37 S. Anderson and J. B. Pendry, J. Phys. C., 5, L41 (1972).

38 T. A. Clarke, R. Mason and M. Tescari, Surface Science, 30, 553 (1972).

39 T. A. Clarke, R. Mason and M. Tescari, Proc. Roy. Soc., in the press.

40 D. G. Fedak and N. A. Gjostein, Surface Science, 8, 77 (1967).

41 R. G. Vranka, L. F. Dahl, P. Chimi and J. Chatt, J. Am. Chem. Soc., 91, 1574 (1969).

42 G. C. Bond, Discussions Faraday Soc., 41, 200 (1966).

${ }^{43}$ I. H. Hillier and V. R. Saunders, Mol. Phys., 22, 1025 (1971). 